\title{
The Relationship Between Trade Openness and Income Distribution in Turkish Economy: Toda-Yamamoto Causality Test Approach
}

\author{
Onur Ercan ${ }^{a}$ \\ a Eskişehir Osmangazi University, Turkey, onurercan.9091@gmail.com, https://orcid.org/0000-0002-9187-6715
}

\section{ARTICLE INFO}

Research Article

2020, Vol. 2(3), 471-486

e-ISSN 2667-5927

Article History:

Received: 19.05.2020

Revised: 01.07.2020

Accepted: 10.07.2020

Available Online:15.07.2020

JEL Code: D31, F60, H2O

Keywords: trade openness, income distribution, stolpersamuelson theory, todayamamoto causality test

Anahtar Kelimeler: ticari dışa açıklık, gelir dağılımı, stolpersamuelson teoremi, todayamamoto nedensellik testi
The Relationship Between Trade Openness and Income Distribution in Turkish Economy: Toda-Yamamoto Causality Test Approach

\section{Abstract}

How the income, which expresses the value obtained by the factor owners as a result of the production process, is distributed among individuals is important for socio-economic development as well as how it is obtained. Because income distribution is affected by many macroeconomic variables and affects economies of the countries. According to the StolperSamuelson Theorem, which explains the effects of free foreign trade on income distribution, the trade liberalization process reveals a trend of equalization in income distribution. The main purpose of the current study is to test Whether income distribution equality of free foreign trade is the cause for Turkey within the framework of the Stolper-Samuelson theorem.

In this study, commercial openness and income distribution inequality relationship was analyzed using data for years 1987-2018 in Turkey by Toda-Yamamoto causality. As a result of the econometric analysis, one-way causality was determined from the real commercial openness to the income distribution inequality.

Türkiye Ekonomisinde Ticari Dışa Açıklık ve Gelir Dağılımı ilişsisi: Toda-Yamamoto Nedensellik Testi Yaklaşımı

$\ddot{O z}$

Faktör sahiplerinin üretim süreci sonucunda elde ettiği değeri ifade eden gelirin, nasıl elde edildiği kadar bireyler arasında nasıl dağıldığı da sosyo-ekonomik kalkınma açısından önem teşkil etmektedir. Çünkü gelir dağılımı birçok makroekonomik değişkenden etkilenerek ülke ekonomilerini etkilemektedir. Serbest dış ticaretin gelir dağılımı üzerindeki etkilerini açıklayan Stolper-Samuelson Teoremi'ne göre, ticaretin serbestleşmesi süreci gelir dağılımında bir eşitlenme eğilimi ortaya çıkarmaktadır. Çalışmanın temel amacı, StolperSamuelson Teoremi çerçevesinde Türkiye için serbest dış ticaretin gelir dağılımı eşitsizliğinin nedeni olup olmadığını test etmektir.

Bu çalışmada, Türkiye için 1987-2018 yıllık verileri kullanılarak ticari dışa açıklık ile gelir dağılımı eşitsizliği ilişkisi Toda-Yamamoto nedensellik testiyle analiz edilmiştir. Ekonometrik analiz sonucunda, reel ticari dışa açıklıktan gelir dağılımı eşitsizliğine doğru tek yönlü bir nedensellik tespit edilmiştir. 


\section{Giriş}

Ekonomik yaşam içerisinde her bir bireyin nihai amacl; sonsuz ihtiyaçlar çerçevesinde faydasını her zaman maksimum yapmaktır. Ekonomi politikalarının nihai amacı ise; ekonomik büyümenin ve istikrarın sağlanması olduğu kadar, toplumu oluşturan bireyler arasındaki gelirin adaletli bir şekilde dağılmasını sağlayarak bireylerin sosyo-ekonomik refah düzeyinin yükseltilmesidir. Ekonomik büyüme sürecinde bireylerin sosyo-ekonomik refah düzeylerinde meydana gelen değişimi incelemenin en iyi yolu; gelir dağılımı verisinde meydana gelen değişime bakmaktır. Kişi başına düşen milli gelirdeki artış ve azalışlar bireylerin refah düzeyleri hakkında bir bilgi verirken, ekonomik büyüme sürecinde meydana gelen bu refah artışının toplumdaki bireyler arasında nasıl dağıldığının incelenmesi bakımından temel alınması gereken en önemli göstergelerden bir tanesi de gelir dağılımı verisidir (Çalışkan, 2010: 91).

Bir toplumda sosyal barış, gelirin birey ve hanehalkları arasında adil bir şekilde dağılmasıyla ve asgari ücretin belli bir seviyenin altına düşmemesiyle sağlanmaktadır. Ancak gelirin, toplumu oluşturan bireyler arasında kendiliğinden adil bir şekilde dağılması mümkün olmamaktadır. Dolayısıyla sosyal devlet anlayışı kapsamında gelirin adil bir şekilde dağılmasının sağlanması için bir devlet müdahalesi gerekmektedir ve bu müdahalenin dozu ülkenin sahip olduğu kaynaklara göre şekillenmekte ve farklılaşmaktadır (Uysal, 2007: 249). Sanayi devrimi sonrasında ortaya çıkan küreselleşme eğilimi, 1980'li yıllarda liberal devlet anlayışının tüm dünyada hâkim olamaya başlamasıyla birlikte daha da hız kazanarak sosyal devlet anlayışının zayıflamasına neden olmuştur. Liberal devlet anlayışının ülkelerce benimsenmesinin sonucunda ekonomi politikalarıyla daha çok ekonomik büyüme ve istikrar hedeflenirken, gelir dağılımı eşitsizliğinin ise uzun dönemde ekonomik büyümeyle birlikte azalacağı ve bireyler arasında bir gelir yakınsamasının gerçekleşeceği varsayılmıştır. Fakat günümüz dünyasında liberal devlet anlayışı, gelirin adil bir şekilde dağılmamasına, bu adil olmayan dağılımın tüm ülkeleri tehdit eden ve çözülmesi gereken sosyo-ekonomik bir sorun olarak ortaya çıkmasına sebep olmuştur. Iktisadi sorun haline gelen gelirin adil bir şekilde dağılmaması sorunu sosyal devlet anlayışının gerekliliğini tekrar ortaya çıkarmış ve toplumdaki en zengin ile en fakir gelir grupları arasındaki gelir farkını azaltacak sosyal politikalar gündeme gelmeye başlamıştır.

Çalışmanın temel amacı, Stolper-Samuelson Teoremi çerçevesinde Türkiye için reel ticaret yoğunluğunun gelir dağılımında bir eşitlenme eğilimi ortaya çıkarıp çıkarmadığını test etmektir. Çalışmada Türkiye'de reel ticaret yoğunluğu ve gelir dağılımı eşitsizliği ilişkisi 1987-2018 yıllık verileri için Toda-Yamamoto nedensellik testi kullanılarak analiz edilmiştir.

Bu ilişki kapsamında, ilk olarak problem teorik olarak araştırılarak temellendirilmiş, sonrasında literatür özeti verilmiş, literatür özeti sonrasında ise ekonometrik analiz sonucunda elde edilen bulgular yorumlanmıştır. 


\section{Literatür Taraması}

\subsection{Ticari Dışa Açıklığın ve Gelir Dağılımının Ölçülmesi}

Tüm dünyayı etkisi altına alan küreselleşme özellikle ekonominin de küreselleşmesiyle hayatımızın önemli ve büyük bir bölümüne nüfuz etmiştir. Ticari serbestleşme ekonominin küreselleşmesinde temel yapı taşlarından bir tanesidir (Özel ve Sezgin, 2013:28). Genel olarak ticari serbestleşme, uluslararası piyasalarda mal ve hizmetlerin serbestçe hareketliliğine olanak tanınmasıdır. Diğer bir ifadeyle ihracat, ithalat ve hizmetlerin dolaşımını sınırlayan hatta engelleyen fiyat müdahalelerinin (tarifeler, vergiler ve ek ücretler) ve tarife ışı engellerin (kotalar, lisans hakları ve yasaklar) ortadan kaldırılmasıdır.

Bir ekonominin ticari serbestleşme düzeyi ticari dışa açıklık ile ölçülmekte ve küreselleşen dünya ekonomisine ne kadar entegre olduğu ticari dışa açıkık düzeyi ile ifade edilmektedir. Literatürde ticari dışa açıklık yöntemi olarak genel kabul görmüş tek bir yöntem bulunmamaktadır. Genelde en çok "politika yansıması temelli ölçüm yöntemi" ve "çıktı temelli ticari dışa açıklık yöntemi" kullanılmaktadır (Spilimbergo, Juan ve Szekely, 1999:96).

Politika yansıması temelli ölçüm yöntemi, fiyat müdahaleleri gibi ticaret politikalarının ticareti ne seviyede etkilediğini ölçmek için kullanılan bir yöntemdir. Fakat bu yöntem tarife dışı müdahaleleri baz almamakta ve bu yöntemde kullanmak için tarifelerle ilgili veriler de yeterli değildir. Bu durum yöntemin eksikliğini gösterdiği için ölçüm yöntemi olarak çok tercih edilmemektedir.

Çıktı temelli ticari dışa açıklık yönteminde ise ele alınan veri setleri birçok ülke için daha kolay temin edilebilecek verilerden meydana geldiği için daha çok tercih edilmekte ve bu da çalışmada kolaylık sağlamaktadır (Spilimbergo, Juan ve Szekely, 1999:96). iktisat yazınında kullanılan çıktı temelli ticari dışa açıkıı yöntemleri Tablo 1 'de gösterilmiştir. 
Tablo 1: Çıktı Temelli Ticari Dışa Açıklık Ölçüm Yöntemleri

\begin{tabular}{|c|c|}
\hline Ölçüm Yöntemi & Ölçümün Tanımı \\
\hline $\mathrm{M}_{\mathrm{i}} / \mathrm{GSYH}_{\mathrm{i}}$ & $\begin{array}{l}\text { İthalat ticaret yoğunluğu; ülkenin ithalatının } \\
\text { GSYH'ye oranlanması ile bulunur. }\end{array}$ \\
\hline $\mathrm{X}_{\mathrm{i}} / \mathrm{GSYH}_{\mathrm{i}}$ & $\begin{array}{l}\text { Ihracat ticaret yoğunluğu; ülkenin ihracatının } \\
\text { GSYH'ye oranlanması ile bulunur. }\end{array}$ \\
\hline$(\mathrm{X}+\mathrm{M})_{\mathrm{i}} / \mathrm{GSYH}_{\mathrm{i}}$ & $\begin{array}{l}\text { Nominal Ticaret yoğunluğu; ülkenin ihracat ve } \\
\text { ithalat toplamının GSYH'ye oranlanması ile bulunur. } \\
\text { Ayarlanmış ticaret yoğunluğu; Singapur ve Hong }\end{array}$ \\
\hline$(\mathrm{X}+\mathrm{M})_{\mathrm{i}} / 2(\mathrm{GSYH}+\mathrm{M})_{\mathrm{i}}$ & $\begin{array}{l}\text { Kong gibi yüksek ithalat yapıp bu ithal malları tekrar } \\
\text { ihraç eden ülkeleri kontrol edebilmek için önerilen } \\
\text { yöntemdir. }\end{array}$ \\
\hline $1-\left[(\mathrm{X}+\mathrm{M})_{\mathrm{i}} / 2 \mathrm{GSYH}_{\mathrm{i}}\right] \times 100$ & $\begin{array}{l}\text { Ayarlanmış ticaret yoğunluğu; Singapur ve Hong } \\
\text { Kong gibi ülkeleri kontrol edebilmek için Frankel } \\
\text { (2000) tarafından önerilen yöntemdir. }\end{array}$ \\
\hline $\mathrm{M} / \mathrm{GSYH}_{\mathrm{i}}-\left(1-\mathrm{GDPi} / \Sigma \mathrm{GSYH}_{\mathrm{i}}\right)$ & $\begin{array}{l}\text { Ayarlanmış ticaret yoğunluğu; Li, Morck, Yang ve } \\
\text { Yeung (2004) tarafından, Frankel (2000)'in }\end{array}$ \\
\hline$(\mathrm{X}+\mathrm{M})_{\mathrm{i}} / \mathrm{rGSYH}_{\mathrm{i}}$ & $\begin{array}{l}\text { Reel ticaret yoğunluğu; Alcalâ ve Ciccone (2004) } \\
\text { tarafından önerilen ve ülkenin ihracat ve ithalat } \\
\text { toplamının reel GSYH'ye bölünmesiyle bulunan bir } \\
\text { yöntemdir. }\end{array}$ \\
\hline
\end{tabular}

Kaynak: Squalli ve Wilson, 2011:1747.

Nominal Ticaret yoğunluğu [(X+M)i/GDPi], çıktı temelli ticari dışa açıklık yöntemleri arasında en çok genel kabul gören ve kullanılan yöntemdir (Squalli ve Wilson, 2011:1745). Ancak Alcalâ ve Ciccone (2004), ticaret ile işgücü verimliliği ilişkisini araştırdıkları çalışmalarında ticarete konu olmayan malların talebinin inelastik olması durumunda, ticarete konu olan mallarda dış ticaretten sağlanan verimlilik artışı, ticarete konu olmayan malların fiyatlarını arttırarak nominal ticaret yoğunluğu oranını düşürebileceğini ileri sürmüşlerdir. Dolayısıyla ekonometrik analizde, reel ticaret yoğunluğu [(X+M)i/rGSYHi] oranının kullanılması gerektiğini, aksi taktirde nominal ticaret yoğunluğu oranının kullanılmasının yanıltıcı bulgulara iteceğini dile getirmişlerdir (Alcalâ ve Ciccone, 2004: 617). Bu yüzden bu çalışmada reel ticaret yoğunluğu oranı kullanılmıştır. Nominal ticaret yoğunluğu oranı da kontrol değişkeni olarak analize dâhil edilmiştir.

Çalışmada gelir dağııımı ölçütü olarak Gini katsayısı kullanılacaktır. Gini katsayısı, bireysel gelir dağılımını ölçmek için genel kabul gören ve oldukça yaygın olarak kullanılan bir ölçüttür. 1912'de Corroda Gini tarafından geliştirilen ve Lorenz Eğrisi baz alınarak oluşturalan Gini katsayısı, eğri ile köşegen arasında kalan alanın, köşegenin altında kalan toplam alan oranına eşittir. Bu oran azaldıkça eşitsizlik azalmakta, arttıkça ise eşitsizlik artmaktadır. Gini katsayısı, 0-1 aralığında değer almakta ve " 0 " gelir dağılımındaki tam eşitliği, "1" ise gelir dağılımındaki tam eşitsizliği ifade etmektedir (Kalaycı ve Öztürk, 2017:155). 


\subsection{Ticari Dışa Açıklık ve Gelir Dağılımı İlişkisi}

1980'li yılların başında ortaya çıkmaya başlayan neoliberal politikalar sosyoekonomik kalkınmanın ticarette serbestleşme ile olacağı anlayışını güçlü kılmış ve ülkeleri ihracata dayalı büyüme modeline geçmeye yönlendirmiştir. Dolayısıyla ticaretin serbestleşmesi ile yaşanmaya başlayan sosyo-ekonomik gelişmelerin gelir dağıımı üzerindeki etkisinin incelenmesi daha da önem arz etmeye başlamıştır (Akın ve Aytun, 2018: 58).

Ticarette serbestleşmenin gelir dağılımına etkisinin teorik temeli Heckscher-OhlinSamuelson (HOS) Teoreminden türetilmiş olan Stolper-Samuelson Teoremine dayanmaktadır (Stolper ve Samuelson, 1974:246). Stolper-Samuelson teoremine göre; ticaretin serbestleşmesiyle ülkeler mukayeseli olarak daha zengin oldukları malların üretiminde uzmanlaşırken, bu süreç sonucunda ülkelerde daha bol bulunan üretim faktörlerine olan talep dolayısıyla bunlara olan ücretler artarken, kıyasla daha az bulunan üretim faktörüne olan talep dolayısıyla bunlara olan ücretler azalacaktır. Gelişmekte olan ülkeler emek faktörü veya kalifiyesiz emek faktörü bakımından daha zengin oldukları için ihracatını emek faktörünü yoğun biçimde gerektiren ürünlerin üretimi ile gerçekleştirmekteyken, gelişmiş ülkeler ise sermaye faktörü veya kalifiyeli emek faktörü bakımından daha zengin oldukları için ihracatını sermaye faktörünü yoğun biçimde gerektiren ürünlerin üretimi ile gerçekleştirmektedirler. Ticarette serbestleşmenin gelişmekte olan ülkelerde emek gelirini veya kalifiyeli olmayan emek gelirini arttıırken, sermaye gelirini veya kalifiyeli emek gelirini azaltmaktadır. Buna karşın gelişmiş ülkelerde ise sermeye geliri artarken, emek geliri azalmaktadır (Gökalp, Baldemir ve Akgün, 2011:89). Stolper-Samuelson teoreminin test edildiği çalışmaların bulguları incelendiğinde ticari dışa açıklık ile gelir dağıımı eşitsizliği arasındaki ilişkinin varlığı genel kabul görürken, bu ilişkinin yönü konusunda bir fikir birliğinin bulunmadığı aşikârdır. Çalışmada yapılacak olan literatür taraması da bu ilişkinin yönü konusundaki belirsizliği ortaya koymaktadır.

Robbins (2003: 2), Güney ülkelerinde ticari dışa açıkıı oranının artması görece daha zengin Kuzey ülkelerden fiziki sermaye transferine olanak tanımakta ve Kuzey ülkelerinde transfer edilen bu fiziki sermayeyi kullanabilecek kalifiyeli emeğin talebini arttırarak ücretlerde artışa neden olmaktadır. Dolayısıyla Güney ülkelerinde kalifiyeli iş̧̧ilerin gelir düzeyi artarken ülke içerisinde gelir dağıımı eşitsizliğine sebep olmaktadır.

Başka bir ifadeyle ticari açıkıı oranı ile gelir dağıımı eşitsizliği arasında istatistiki olarak anlamlı pozitif bir sonuç elde etmiştir. Benzer konuda çalışma yapan Bhatta (2002), gelişmekte olan ve gelişmiş ekonomiler için 1960-1989 yıllarını baz alarak gelir dağılımı eşitsizliği ile ticari dışa açıklık oranı arasındaki ilişkiyi Johansen eşbütünleşme metodu ile araştırdığı çalışmasında bu değişkenler arasında pozitif 
yönlü anlamlı bir ilişki gözlemlemiştir. Dreher ve Noel (2006), OECD ülkeleri için 1970-2000 dönemi verilerini baz alarak yaptığı çalışmada KOF İsviçre Ekonomi Enstitüsü tarafından oluşturulan KOF küreselleşme indeksi ile gelir dağılımı eşitsizliği ilişkisini incelemiştir. Çalışma sonucunda küreselleşmenin gelişmiş ekonomilerde gelir dağılımı eşitsizliğini daha çok, gelişmekte olan ekonomilerde ise daha az arttırdığını ortaya koymuştur. Bergh ve Nilsson (2010), 79 ülke için 19702005 yılları verilerini kullanarak KOF küreselleşme indeksi ile Fraser Enstitüsü tarafından oluşturulan ekonomik özgürlük indeksi ve gelir dağılımı arasındaki ilişkiyi GMM tahmincisi yöntemini kullanarak analiz etmişlerdir. Analiz sonucunda; ekonomik özgürlüğü destekleyici politikaların artmasının gelişmiş ekonomilerde gelir dağılımı eşitsizliğini arttıracağı, az gelişmiş ve gelişmekte olan ekonomilerde ise gelir dağılımı eşitsizliğini azaltacağı kanısına varmışlardır. Gökalp, Baldemir ve Akgün (2011), Türkiye'de ticari dışa açıklığın gerek kalifiyeli gerekse kalifiyesiz emeğin gelirlerini azaltarak gelir dağılımı eşitsizliğine neden olduğu sonucuna ulaşmışlardır. Oransay (2016), Türkiye imalat sanayi alt sektörleri için 1988:Q12011:Q4 dönemi üçer aylık verilerini kullanarak ticari dışa açıklığın ücretler üzerindeki etkisini analiz etmiştir. Analiz sonucunda, ticari dışa açıklığın ücretler üzerindeki etkisinin negatif olduğu tespit etmiştir. Dolayısıyla, ticari dışa açıklık ile ücretler arasında negatif yönlü bir ilişki olduğu sonucuna ulaşmıştır (Oransay, 2016:88). Bükey ve Çetin (2017), Türkiye'de küreselleşme, enflasyon ve faiz değişkenlerinin gelir eşitsizliği üzerindeki etkisini 1980-2014 yıllık verilerini kullanarak En Küçük Kareler yöntemiyle incelemiştir. Analiz sonucunda, küreselleşme, enflasyon ve faiz değişkenleri ile gelir eşitsizliği arasında anlamlı ve pozitif bir sonuç elde etmiştir. Küreselleşmedeki, enflasyondaki ve faiz değişkenlerindeki bir birimlik artış gelir eşitsizliğini sırasıyla yaklaşık olarak 0.53, 0.06 ve 0.05 birim arttırmaktadır (Bükey ve Çetin, 2017:115). Acaravcı, Erdoğan ve Artan (2018), Balkan ülkelerinde reel gelir, demokrasi ve ticari dışa açıklığın gelir dağılımı eşitsizliği üzerindeki etkisi 1996-2010 dönemi yılık verilerini kullanarak panel veri analiziyle incelemişlerdir. Analiz sonucunda, reel gelir, demokrasi ve ticari dışa açıklıktan gelir dağılımı eşitsizliğine doğru tek yönlü bir nedensellik tespit etmişlerdir.

Gelişmiş ekonomilerde ithalat, emek yoğun (kalifiyeli olmayan emek) sektörler tarafından üretilen ürünlerin fiyatlarını düşürürken, ulusal firmalar üretimlerini sermaye yoğun (kalifiyeli emek) sektörler tarafından üretilen ürünlerin üretimine kaydırır.

Bunun sonucunda gelişmiş ekonomilerde gelir eşitsizliğimin artmasında gelişmekte olan ekonomilerle yapılan ticaret önemli bir rol oynamaktadır (Slaughter ve Swagel, 1997:6). Ticaretin liberalleşmesi sürecinde gelişmiş ekonomilerde kalifiyesiz emekten kalifiyeli emeğe doğru bir talep artışı meydana gelmektedir. Bu talep artışı kalifiyeli ve kalifiyesiz emek arasında gelir dağılımı eşitsizliğine yolar açarken, aynı zamanda kalifiyesiz işçilerin işsizlik oranlarında bir artışa sebep olmaktadır. ABD'de 1980'li yılların başlarına doğru kalifiyeli emek ücretleri kalifiyesiz emek ücretlerine göre daha fazla artış göstermiştir (Slaughter ve Swagel, 1997:3). Benzer şekilde 
Fransa'da 1990'lı yılların başlarında kalifiyeli işçi işsizlik oranı $(\% 4,5)$ ile kalifiyesiz işçi işsizlik oranı (\%20) arasındaki fark kalifiyesiz işçilerin aleyhine olacak şekilde $\% 15,5^{\prime}$ lere kadar çıkmıştır. Bunun sebebi ise kalifiyeli işçilerin, kalifiyesiz işçilerin yapabileceği işleri de yapabilmesidir. (Cohen, 2007:56). Heshmati (2004), 62 ülke için 1995-2001 yıllarını baz alarak ticari serbestleşme ile gelir dağılımı eşitsizliği arasındaki ilişkiyi incelemiştir. Analiz sonucunda, ticari serbestleşmenin gelir dağılımı eşitsizliğini \%7-\%11 arasında açıklayabildiğini elde etmişlerdir.

Dollar ve Kraay (2004: 22), 68 az gelişmiş ve gelişmekte olan ülkeler için ticari açıklık oranı ile gelir dağılımı eşitsizliği arasındaki ilişkiyi incelediği çalışmasında Robbins (2003) ve Bhatta (2002)'nin elde ettiği sonuca karşıt bir sonuç elde etmiştir. Elde ettiği sonuç; gelir dağılımı eşitsizliği ile ticari açıklık oranı arasında negatif yönlü bir ilişkinin olduğudur. Başka bir ifadeyle ticari dışa açıklıktaki artışlar gelir dağılımı eşitsizliğini azaltarak gelir dağılımını iyileştirmektedir. Gelir dağılımı eşitsizliği ile ticari açıklık oranı arasındaki ilişkiyi 24 OECD ülkesini temel alarak araştıran Faustino ve Vali (2011:18), Dollar ve Kraay (2004)'ün elde ettiği sonucu destekleyici bulgulara ulaşmıştır. ARDL yöntemi ile gelir dağılımının belirleyicilerinin araştırıldığı çalışmada ekonomik büyüme ve ticari dışa açıklığın gelir dağılımı eşitsizliğini azaltıcı bir etkisinin olduğu sonucuna ulaşmışlardır (Dişbudak ve Süslü, 2007). Gülmez ve Altıntaş (2015), Türkiye için 1981-2011 dönemine ait yıllık verilerini kullanarak ticari açıklık ve enflasyon ile gelir dağılımı eşitsizliği ilişkisini Johansen eşbütünleşme testi ve vektör hata düzeltme testiyle incelemiştir. İnceleme sonucunda, hem kısa hem de uzun dönemde ticari açıklıktan ve enflasyondan gelir dağılımı eşitsizliğine doğru tek yönlü bir granger nedensellik tespit etmişlerdir. Etki-tepki analizi sonucunda ticari dışa açıklığın ve enflasyonun gelir dağılımı eşitsizliği üzerinde azaltıcı bir etkiye sahip olduğunu ortaya koymuşlardır. Dollar ve Kraay (2004), Faustino ve Vali (2011), Dişbudak ve Süslü (2007) ve Gülmez ve Altıntaş (2015) Stolper-Samuelson Teoremini destekleyici sonuçlar ortaya koymuşlardır. Bükey ve Akgül (2019), Türkiye'de teknoloji ihracatı ve ithalatı ile gelir dağılımı eşitsizliği ilişkisini 1990-2016 yıllık verilerini kullanarak En Küçük Kareler yöntemi ile analiz etmiştir. Ekonometrik analiz sonucunda, teknoloji ihracatındaki bir birimlik artış gelir eşitsizliğini katsayısını yaklaşık olarak \%0.18 puan arttırırken, teknoloji ithalatındaki bir birimlik artış ise gelir eşitsizliği katsayısı yaklaşık olarak \%0.11 puan azaltmaktadır (Bükey ve Akgül, 2019:7).

Gelir dağılımı eşitsizliği ile ticari dışa açıklık oranı arasında bir ilişkinin olmadığı sonucuna ulaşan çalışmalar da iktisat yazınında mevcuttur. Li, Squire ve Zou (1998), Vivarelli (2004) ve Sehar, Adiqa, Azra ve Ahsan (2013) farklı zaman dilimlerinde yaptıkları çalışmalarda gelir dağılımı ile ticari açıklık oranı arasında istatistiki olarak anlamlı herhangi bir sonuca ulaşamamışlardır. 


\section{Yöntem}

Engle-Granger (1988) metodu, uzun dönemde en az iki seri arasındaki ilişkinin incelenmesinde literatürde en sık kullanılan Eş-bütünleşme testlerinden biridir. Granger nedenselliğin test edilmesindeki amaç; bir serinin hareketlerinin sistematik olarak hem kendi hem de başka bir serinin gecikmeli değerinden etkilenip etkilenmediğini belirleyerek analizde bulunmaktır. Ayrıca gecikme sayısına oldukça duyarlı olan Granger nedensellik testinde, belirlenen her farklı gecikme sayısında farklı sonuçlar gözlemlenebilmektedir. Dolayısıyla, uygun gecikme sayısının belirlenmesi bu test için önem teşkil etmektedir. Uygulanabilirliğinin yüksek olmasında dolayı bu metoda sıkça ekonometrik analizlerde yer verilse de bazı eksikleri de söz konusu olmaktadır. Eş-bütünleşik olup olmadığı incelenecek olan serilerin öncelikle durağan olması ve tüm serilerin aynı dereceden Eş-bütünleşik olması gerekmektedir. Fakat Toda ve Yamamoto (1995) tarafından geliştirilen ve serilerin gecikmesi genişletilmiş VAR yöntemine dayanan Toda-Yamamoto nedensellik testinde ise serilerin birim köke sahip ve derecelerinin eş-bütünleşik olup olmadığını dikkate almaksızın nedensellik analizi yapılmasına imkân tanımaktadır (Çalışkan, Karabacak ve Meçik, 2017:50).

Toda-Yamamoto nedensellik testi, optimal gecikme sayısı ( $p$ ) ve serilerin maksimum durağanlık derecesine $\left(d_{\max }\right)$ bağlı olarak oluşturulan bir $\operatorname{VAR}\left(p+d_{\max }\right)$ modeline dayalı olarak tahmin edilmektedir (Akçay, 2011:84). Ayrıca serilerin maksimum durağanlık derecesinin $\left(d_{\max }\right)$, VAR modelinin optimal gecikme sayısını geçmemesi koşulu ile Toda-Yamamoto nedensellik testi uygulanabilmektedir (Çalışkan, Karabacak ve Meçik, 2017:50). VAR modeline dayalı olarak tahmin edilen TodaYamamoto modeli eşitlik (1)'de verilmiştir.

$$
X_{t=6}+a_{1} X_{t-1}+\ldots . .+a_{p} X_{t-p}+\ldots . .+a_{p+1} X_{t-p-d}+\varepsilon_{t}
$$

Eşitlik (1)'de 6 , bir sabit vektörü, $p$, uygun gecikme uzunluğunu, $d$, maksimum eşbütünleşme derecesini, $\varepsilon$, hata terimleri vektörünü ve $a$ parametreler matrisini göstermektedir. Seriler arasındaki nedensellik ilişkisi, $H_{0}: a_{1}=0$ hipotezi aracılığıyla WALD testi kullanılarak tahmin edilmektedir. Hesaplanan WALD test istatistiği, tablo değerinden büyük ise hipotez reddedilmektedir (Gazel, 2017:292).

\section{Veri}

Ekonometrik analizde Türkiye için 1987-2018 yıllarına ait Gini indeksi ve ticari dışa açıklık oranı değişkenleri kullanılmıştır. Bağımlı değişken gelir dağılımı eşitsizliğine (GINi) ait veri lowa Üniversitesi öğretim üyesi Prof. Dr. Frederick Solt tarafından oluşturulmuş "The Standardized World Income Inequality Database'den" temin edilmiştir. Nominal ticari dışa açıklık [(ihracat+ithalat)/GSYH] ile reel ticari dışa açıklığı [(ihracat+ithalat)/rGSYH] hesaplamakta kullanılacak olan nominal ve reel GSYH, ithalat ve ihracat verileri World Bank Database'den derlenmiştir. Çalışmadaki değişkenler, logaritması alınarak ekonometrik analize dâhil edilmiştir. Bağımlı 
değişken olan Gini indeksi (LNGINI), bağımsız değişkenlerden reel ticari dışa açıklık (LNRTDA) ve nominal ticari dışa açıklık ise (LNNTDA) olarak ifade edilmiştir.

\section{Ampirik Bulgular}

Toda-Yamamoto nedensellik testi, serilerin durağan olması koşulunu göz önünde bulundurmasada, maksimum bütünleşme derecesinin $\left(d_{\max }\right)$ bulunması için Augmented Dickey-Fuller (ADF) ve Phillips-Peron (PP) birim kök testleri yapılmıştır.

\subsection{Birim Kök Testi Sonuçları}

Tablo 2: Gelir Dağılımı Eşitsizliği (LNGINI) Serisi İçin Birim Kök Testleri

\begin{tabular}{lcccc}
\hline \hline & \multicolumn{2}{c}{ Düzey } & \multicolumn{2}{c}{ Birinci Fark } \\
\hline \hline & Sabit & Sabit ve Trend & Sabit & Sabit ve Trend \\
ADF & $0.4304[0.8913]$ & $-2.0557[0.5484]$ & $-2.7553[0.0769]$ & $-2.5269[0.3139]$ \\
PP & $0.2485[0.9714]$ & $-2.5647[0.2976]$ & $-2.7036[0.0852]$ & $-2.4868[0.3317]$ \\
\hline \hline
\end{tabular}

Tablo 3: Reel Ticari Dışa Açıklık (LNRTDA) Serisi İçin Birim Kök Testleri

\begin{tabular}{lcccc}
\hline \hline & \multicolumn{2}{c}{ Düzey } & \multicolumn{2}{c}{ Birinci Fark } \\
\hline \hline & Sabit & Sabit ve Trend & Sabit & Sabit ve Trend \\
ADF & $-1.5676[0.4867]$ & $-0.6104[0.9712]$ & $-4.8326[0.0005]$ & $-5.1078[0.0014]$ \\
PP & $-1.5506[0.4951]$ & $-0.7202[0.9625]$ & $-4.8333[0.0015]$ & $-5.1021[0.0014]$ \\
\hline \hline
\end{tabular}

Tablo 4: Nominal Ticari Dışa Açıklık (LNNTDA) Serisi İçin Birim Kök Testleri

\begin{tabular}{lcccc}
\hline \hline \multicolumn{2}{c}{ Düzey } & \multicolumn{2}{c}{ Birinci Fark } \\
\hline \hline & Sabit & Sabit ve Trend & Sabit & Sabit ve Trend \\
ADF & $-1.1102[0.6990]$ & $-4.1918[0.0128]$ & $-4.7407[0.0007]$ & $-4.6827[0.0040]$ \\
PP & $-0.5648[0.8645]$ & $-2.5949[0.2849]$ & $-5.5576[0.0001]$ & $-5.2937[0.0009]$ \\
\hline \hline
\end{tabular}

ADF ve PP birim kök test sonuçlarına göre; Gini indeksi değişkeni ikinci farkında durağanlaşırken, reel ve nominal ticari dışa açıklık değişkenleri birinci farkında durağandır. Dolayısıyla Gini indeksi değişkeni ikinci dereceden bütünleşik [I(2)] iken, reel ve nominal ticari dışa açıklık değişkenleri ise birinci dereceden bütünleşiktir [I(1)]. Bu sebeple, analiz için maksimum bütünleşme derecesi 2 (dmax= 2) olarak belirlenmiştir. Dmax= 2 olarak belirlendikten sonra VAR modeli için uygun optimal gecikme sayısının (p) belirlenmesi gerekmektedir. Uygun optimal gecikme sayısını belirlemek için öncelikle Gini ve ticari dışa açıklık değişkenleri ile bir VAR modeli oluşturulmuş, sonrasında ise bilgi kriterlerine göre uygun " $p$ " tahmin edilmiştir (Çalışkan, Karabacak ve Meçik, 2017:51-52). Bilgi kriterlerine göre belirlenen uygun optimal gecikme sayısının VAR modeli için istikrar koşulunu sağlayıp, sağlamadığını 
test etmek için AR polinomunun ters köklerine bakılmaktadır. Dolayısıyla AR karakteristik polinomunun ters köklerinin hepsi birim çember içinde yer alıyorsa belirlenen $p$, VAR modeli için uygun optimal gecikme sayısı olduğunu göstermektedir.

\section{Şekil 1: AR Karakteristik Polinomunun Ters Kökleri Inverse Roots of AR Characteristic Polynomial}

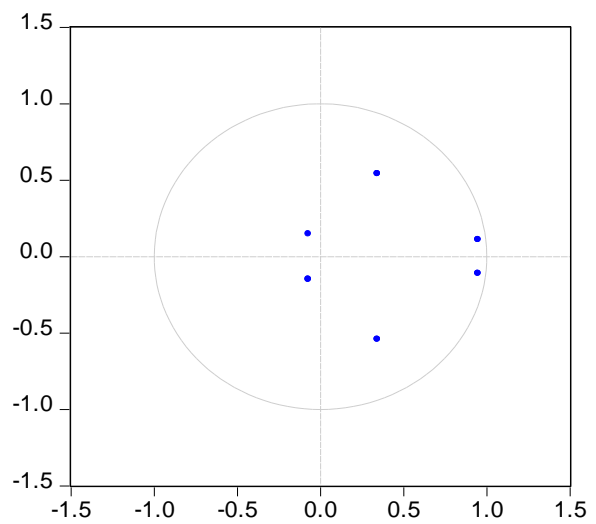

Şekil 1'e göre AR polinomunun ters köklerinin hepsi birim çember içinde yer aldığı için $\operatorname{VAR}(p=6)$ modelinin istikrar koşulunu sağladığını göstermektedir.

Bununla birlikte, Tablo 5'e göre modelde otokorelasyon ve Tablo 6'ya göre ise modelde değişen varyans probleminin söz konusu olmadığı da görülmektedir.

Tablo 5: VAR ( $p=6$ ) Modeli İçin Otokorelasyon LM Test Sonuçları

\begin{tabular}{ccc}
\hline \hline Gecikme & LM istatistiği & Prob. \\
1 & 6.411593 & 0.6981 \\
2 & 3.688873 & 0.9307 \\
3 & 12.13806 & 0.2056 \\
4 & 4.026782 & 0.9096 \\
5 & 12.84265 & 0.1699 \\
6 & 6.414923 & 0.6978 \\
7 & 4.392247 & 0.8838 \\
8 & 14.76402 & 0.1976 \\
9 & 4.582935 & 0.8690 \\
10 & 5.779157 & 0.7618 \\
11 & 11.09529 & 0.2692 \\
12 & 4.026782 & 0.4417 \\
\hline \hline
\end{tabular}


Tablo 6: VAR ( $\mathrm{P}=6)$ Modeli İçin Değişen Varyans Testi

\begin{tabular}{ccc}
\hline \hline \multicolumn{3}{c}{ White Değişen Varyans Testi } \\
\hline \hline Ki-kare & Serbestlik Derecesi & Prob. \\
76.17109 & 72 & 0.3459 \\
\hline \hline
\end{tabular}

Toda-Yamamoto nedensellik testi için uygun gecikme sayısı $\left(p+d_{\max }\right)$ şeklinde belirlenmektedir. Bu çalışmada Toda-Yamamoto nedensellik testi için uygun gecikme sayısı $\left[(p=6)+\left(d_{\max }=2\right)\right]=8$ olarak belirlenmiş ve belirlenen 8 gecikme sayısına göre nedensellik testi yapılmıştır. Test sonuçları tablo 7'de verilmiştir.

Tablo 7: Toda-Yamamato Nedensellik Testi Sonuçları

\begin{tabular}{cccc}
\hline \hline Model & $\mathbf{p}+\mathbf{d}_{\max }$ & Olasılık Değeri & Nedenselliğin Yönü \\
\hline \hline LNRTDA-LNGINI & $6+2=8$ & 0.0324 & LNRTDA $\rightarrow$ LNGINI \\
LNGINI-LNRTDA & $6+2=8$ & 0.1973 & --- \\
LNNTDA-LNGINI & $6+2=8$ & 0.1256 & -- \\
LNGINI - LNNTDA & $6+2=8$ & 0.0000 & LNGINI $\rightarrow$ LNNTDA \\
LNRTDA - LNNTDA & $6+2=8$ & 0.0002 & LNRTDA $\rightarrow$ LNNTDA \\
LNNTDA - LNRTDA & $6+2=8$ & 0.5794 & -- \\
\hline \hline
\end{tabular}

Tablo 7'deki sonuçlara göre, reel ticari dışa açıklığın (LNRTDA) gelir dağılımı eşitsizliğinin (LNGINI) nedeni olmadığı sıfır hipotezi reddedilirken, gelir dağılımı eşitsizliğinin reel ticari dışa açıklığın nedeni olmadığı sıfır hipotezi reddedilememiştir. Diğer bir ifadeyle LNRTDA'dan LNGINI'ye doğru tek yönlü bir nedensellik vardır. Nominal ticari dışa açıklığın (LNNTDA) gelir dağılımı eşitsizliğinin (LNGINI) nedeni olmadığı sıfır hipotez reddedilemezken, LNGINI'nın LNNTDA'nın nedeni olmadığı sıfır hipotez reddedilmiştir. Başka bir ifadeyle test sonuçları LNGINI'den LNNTDA'ya doğru tek yönlü bir nedensel ilişkiye işaret etmektedir. Analiz sonucunda bağımsız değişkenler arasında LNRTDA'dan LNNTDA'ya doğru tek yönlü bir nedensellik ilişkisi de tespit edilmiştir.

\section{Tartışma ve Sonuç}

Toplumu oluşturan bireylerin daha mutlu bir yaşam ve toplum ile barışık bir ilişki sürdürebilmesi, gelirin adil bir şekilde bölüşülmesiyle mümkün olmaktadır. 1980 sonrası dönemde hâkim olan liberal devlet anlayışı, önceliği ekonomik büyümeyle ilgili sorunlara ayırırken, gelir dağılımı eşitsizliği ve yoksulluk sorunu ikinci planda kalmıştır. Liberal devlet anlayışınca uzun dönemde büyümeyle birlikte toplumun en alt tabakasını oluşturan yoksul vatandaşların gelirlerinin yüksek gelirlileri yakınsayarak gelir eşitsizliğinin kendiliğinden çözüleceği varsayılmıştır. Fakat üretim artışıyla birlikte gelir dağılımı daha çok bozulmuş ve gelir dağılımı eşitsizliği önemli bir sosyo-ekonomik sorun olarak ortaya çıkmıştır. Ülke ekonomilerinin 
sürdürülebilirliği açısından gelirin nasıl elde edildiği kadar nasıl dağıldığı da iktisadi bir önem taşımaktadır.

1980'den bugüne gelindiğinde ticaretin liberalleşmesi, üretim faktörlerini etkilemekle beraber gelir dağılımını da etkilemiştir. Ticaretin liberalleşmesinin gelir dağılımı üzerindeki etkilerini açıklayan Stolper-Samuelson Teoremi göre, ticaretin liberalleşmesi sürecinin ülkelerin mukayeseli olarak daha zengin oldukları üretim faktörlerinde talebi arttırırken, daha az zengin olukları üretim faktörlerinde ise talebini azaltmaktadır. Bu nedenle, talebi artan üretim faktörlerinin gelirlerini arttırırken, talebi azalan üretim faktörlerinin ise gelirlerini azaltarak gelir dağılımında bir eşitlenme eğilimi ortaya çıkaracaktır. Ancak bu teorem ticaretin liberalleşmesinin gelir dağılımı eşitsizliğini azaltıcı etkileri olabileceğini işaret etmekle birlikte, konu ile ilgili teorik ve ampirik çalışmalardan elde edilen bulgular incelendiğinde ülkelerin farklı gelişmişlik düzeylerine sahip olmasından dolayı bu ilişkinin yönü belirsizdir.

Türkiye için 1987-2018 yılık verileri kullanılarak ticari dışa açıklık ile gelir dağılımı eşitsizliği ilişkisinin Toda-Yamamato nedensellik testiyle incelendiği bu çalışmada, reel ticari dışa açıklıktan gelir ağılımı eşitsizliğine doğru tek yönlü bir nedensellik tespit edilmiştir. Bununla beraber hem gelir dağılımı eşitsizliği hem de reel ticari dışa açıklık, nominal ticari açıklığın granger nedeni olduğu sonucu da elde edilmiştir. $\mathrm{Bu}$ sonuçlar, Stolper-Samuelson teoreminde öne sürülen gelir dağılımında bir yakınsamanın gerçekleşeceği hipotezini desteklememektedir. Bunun sebeplerinden bir tanesi yabancı yatırımlardır. Serbest dış ticaret ile birlikte doğrudan yabancı yatırımlar ve portföy yatırımları yüksek kar ve verimlilik dürtüsüyle hareket ederek toplam gelirden aldıkları payı arttırabilmek için teknoloji yoğun sektörlere kanalize olmakta ve bu sektördeki kalifiyeli emeğe olan talep dolayısıyla da kalifiyeli emeğin gelirleri artmaktadır. Öte yandan toplam işgücünün büyük bir kısmını oluşturan tarım sektöründeki kalifiyeli olmayan emeğe ise talep azalmakta ve kalifiyesiz iş̧̧ilerin işsizlik oranında bir artış meydana gelmektedir. Bununla birlikte iç yatırımların belli bölgelerde yoğunlaşması ve bu yatırımların tarım sektörüne kanalize edilememesinden dolayı kırsal alanlarda işsizliğin daha da çok artmasıdır. Diğer bir sebebi ise teknolojik gelişmelerdir. Dünya genelinde yaşanan teknolojik gelişmeler serbest dış ticaret yoluyla ülkelerdeki katma değeri düşük emeğin teknoloji ve katma değeri yüksek emek ile ikame edilebilmesine imkân tanımıştır. İşsizlikle birlikte ikame edilebilme durumu katma değeri düşük emek talebi üzerindeki baskıyı arttırarak toplam gelir içindeki payının azalmasıdır.

Liberal devlet anlayışı ile bağdaşmamakla beraber piyasa başarısızlıklarının giderilebilmesi için sosyal devlet anlayışının bir gereği olan devletin ekonomiye müdahalesinin gerekliliği birçok iktisatçı tarafından kabul edilmektedir. Devletin asgari ücret düzeyini yükselterek ve o ücret düzeyinin altında emek istihdam edilmesini yasaklayarak en yüksek gelirli ile en düşük gelirli grup arasındaki gelir farkı azaltabilecektir. Fakat toplam gelirin adil bir şekilde dağılımının sürdürülebilmesinde asgari ücret uygulaması yeterli olmayacaktır. Bunun vergi 
politikası, sübvansiyonlar ve sosyal yardımlar gibi maliye politikası araçları ile desteklenmesi gerekmektedir.

Tüketim üzerinden alınan dolaylı vergilerin toplam vergi gelirleri içerisindeki oranı azaltılırken, servet ve gelir üzerinden alınan dolaysız vergilerin toplam vergi gelirleri içerisindeki oranının arttırılması düşük gelirli grubun refah seviyesinde bir artış doğuracaktır. Başka bir yönden ise zorunlu tüketim mallarının lüks tüketim mallarına oranla daha düşük vergilendirilmesi gibi politikalar vergilerin gelir dağılımı eşitsizliğini arttırıcı yönü nispeten engellenmiş olacaktır. Toplumun en alt tabakasını oluşturan yoksul kesimin temel ihtiyaçları olan mal ve hizmet fiyatlarının sübvansiyonlar aracılığıyla sübvanse edilerek fiyatlarının düşürülmesi düşük gelirli grubun satınalma gücünü arttırarak refah düzeyini yükseltecektir. Dolayısıyla gelir dağılımındaki bozulma kısmen de olsa önlenmiş olacaktır. İşsizlik, yaşlılık, engellilik ve yeterli gelire sahip olunmaması gibi sebeplerle yardıma muhtaç kişilere sosyal devlet anlayışının bir gerekliliği olarak bu kişilere sosyal yardımda bulunulması gelir eşitsizliğini bu yoksul kesimin lehine dönüştürecektir. Ayrıca uzun vadeli ekonomi politikalarıyla yatırımların emek yoğun (kalifiyesiz emek yoğun) sektörlere kanalize edilmesi ve firmalara verilecek kalkınma teşviklerin, hibelerin firmaların emek yoğun sektörlerde faaliyette bulunmasını ve bulunmalarını destekler nitelikte olması gelir dağılımı eşitsizliğini azaltıcı bir etkisinin olacağı önemi de göz önünde bulundurulmalıdır.

Bu çalışmada elde edilen bulgular, Bhatta (2002), Robbins (200 3), Heshmati (2004), Dreher ve Noel (2006) ve Gökalp, Baldemir ve Akgün (2011)'in bulgularıyla paralellik göstermektedir. Ayrıca Slaughter ve Swapel (1997), Cohen (2007) ve Bergh ve Nilsson (2010) gelişmiş ülkeler için ticari dışa açıklık ile gelir dağılımı ilişkisini inceledikleri çalışmalarında ticari dışa açıklığın gelir dağılımı eşitsizliğinin granger nedeni olduğu sonucuna ulaşmışlardır. Gelişmekte olan ülke konumundaki Türkiye için yapılan bu çalışmada da gelişmiş ülkelerde olması muhtemel sonuçlarla benzer sonuçlara ulaşılmıştır. 


\section{Kaynaklar}

Acaravcı, A., Erdoğan, S., \& Artan, S. (2018). Gelir dağılımı, demokrasi, reel gelir ve dışa açıklık ilişkisi: Balkan Ülkeleri için ampirik bir uygulama. Mediterranean International Conference on Social Sciences by UDG, 1(1). 167-173.

Akçay, S. (2011). Causality relationship between total r\&d investment and economic growth: evidence from United States. Süleyman Demirel Üniversitesi iktisadi ve Idari Bilimler Fakültesi Dergisi, 16(1): 79-92.

Akın, S., \& Aytun, C. (2018). Gelir dağılımının makroekonomik belirleyicileri: Türkiye örneği. Mustafa Kemal Üniversitesi Sosyal Bilimler Enstitüsü Dergisi, 15(42), 52-81.

Alcalâ, F., \& Ciccone, A. (2004). Trade and productivity. Quarterly Journal of Economics, 119(2), 613-646.

Bergh, A., \& Nilsson T. (2010). Do liberalization and globalization increase income inequality?. European Journal of Political Economy, 26(4), 488-505.

Bhatta, S. (2002). Has the increase in world-wide openness to trade worsened global income inequality. Regional Secience, 81(2), 177-196.

Bükey, A. M., \& Çetin, B. I. (2017). Türkiye'de gelir dağılımına etki eden faktörlerin en küçük kareler yöntemi ile analizi. Maliye Araştırmalar Dergisi, 3(3), 103-117.

Bükey, A. M., \& Akgül, O. (2019). Teknoloji Transferinin Gelir Dağılımına Olan Etkisi: Türkiye Örneği. Siyaset, Ekonomi Ve Yönetim Araştırmaları Dergisi, 7(1), 1-8.

Cohen, D. (2007). The Wealth of the World and the Poverty of Nations. (Çev. D. Hattatoğlu) (Ed) C. Belge, Dünyanın zenginliği ulusların fakirliği. İstanbul: İletişim Yayınları.

Çalışkan, Ş. (2010). Türkiye'de Gelir Eşitsizliği ve Yoksulluk. Sosyal Siyaset Konferansları Dergisi, 2(59), 89-132.

Çalışkan, Ş., Karabacak, M., \& Meçik, O. (2017). Türkiye ekonomisinde eğitim harcamaları ve ekonomik büyüme ilişkisi: Bootstrap Toda-Yamamoto nedensellik testi yaklaşımı. Kocaeli Üniversitesi Sosyal Bilimler Enstitüsü Dergisi, 33 (1), 45-56.

Dişbudak, C., \& Süslü, B. (2007). Türkiye'de kişisel gelir dağılımını belirleyen makroekonomik faktörler. Ekonomik Yaklaşım, 65(18), 3-25.

Dollar, D., \& Kraay, A. (2004). Trade, growth, and poverty. The Economic Journal, 114(493), 22-49.

Dreher, A., \& Noel, G. (2006). Has globalization increased inequality. KOF Working Papers, 6-140.

Faustino, H., \& Vali, C. (2011). The effects of globalization on OECD income inequality: A static and dynamic analysis, Working Paper 12. 
Frankel, J.A. (2000). Assessing the efficiency gains from further liberalization. Harvard KSG Faculty Research Working Paper, No. RWP01-030.

Gazel, S. (2017). BiST sınai endeksi ile çeşitli metaller arasındaki ilişki: TodaYamamoto nedensellik testi. Akademik Sosyal Araştırmalar Dergisi, 5(52), 287-299.

Gökalp, M. F., Baldemir, E., \& Akgün, G. (2011). Türkiye ekonomisinde dışa açılma ve gelir eşitsizlikleri ilişkisi. Yönetim ve Ekonomi Dergisi, 18(1), 88-104.

Granger, C. W. J. (1988). Some recent developments in the concept of causality. Journal of Econometrics, 39, 199-211.

Gülmez, A., \& Altıntaş, N. (2015). Türkiye'de ticari açıklık ve enflasyonun gelir dağılımına etkisi: Ekonometrik bir analiz. Kafkas Üniversitesi Iktisadi ve Idari Bilimler Fakültesi Dergisi, 6(9), 31-44.

Heshmati, A. (2004). The relationship between income inequality, poverty and globalization. United Nation University Research, Paper No: 2005/37.

Kalaycı, S., \& Öztürk, A. (2017). Türkiye'de eğitim, işsizlik ve enflasyona dayalı gelir dağılımı adaletsizliği. Turkish Studies International Periodical for the Languages, Literatureand History of Turkishor Turkic, 12(31), 151-168.

Li, K., Morck, R., Yang, F., \& Yeung, B. (2004). Firm-specific variation and openness in emerging markets. The Review of Economics and Statistics, 86(3), 658-69.

Li, H., Squire, L., \& Zou, H. (1998). Explaining international and intertemporal variation in income inequality. Economic Journal, 108, 26-43.

Oransay, G. (2016). Dışa açıklığın ücretlere etkisi: Türkiye üzerine ampirik bir uygulama. Niğde Üniversitesi Iktisadi ve Idari Bilimler Fakültesi Dergisi, 9(3). 74-90.

Özel, H. A., \& Sezgin, F. H. (2013). Türkiye'de ekonomik açıklık ve işsizlik ilişkisinin zaman serisi analiziyle incelenmesi. Trakya Üniversitesi Iktisadi ve Idari Bilimler EDergi, 2(2), 26-46.

Robbins, D. J. (2003). The impact of trade liberalization upon inequality in developing countries: a review of theory and evidence. ILO Working Paper, No: 13.

Sehar, M., Adiqa, K.K., Azra, K., \& Ahsan, J. (2013). The relationship between trade openness and income inequalities. Turkish Economic Association International Conference On Economics Ice-Tea 2013.

Slaughter, M. J., \& Swagel, P. (1997). Does globalization lower wages and export jobs?. IMF Economic Issues 11.

Solt, F. (2019). Measuring income inequality across countries and over time: The Standardized World Income Inequality Database, SWIID Version 8.2. 
Spilimbergo, A., Juan L. L., \& Szekely M. (1999). Income distribution, factor endowments, and trade openness. Journal of Development Economics, 59, 77-101.

Stolper, W., \& Samuelson, A. P. (1974). Protection and real wages. (Ed.) J. Bhagwati, International trade (ss. 245-268). England: Penguin Education.

Squalli, J., \& Wilson, K. (2011). A new approach to measuring trade openness. The World Economy, 34(10), 1745-1770.

Toda, H. Y., \& Yamamoto, T. (1995). Statistical inference in vector autoregressions with possibly integrated processes. Journal of Econometrics, 66, 225-250.

Uysal, Y. (2007). Gelir dağıımı türleri arasındaki ilişkiler perspektifinde Türkiye'de gelir dağıımının düzenlenmesine yönelik öneriler. Dokuz Eylül Üniversitesi Sosyal Bilimler Enstitüsü Dergisi, 9(2), 248-292.

Vivarelli, M. (2004). Globalization, skills and within-country income inequality in developing countries. (Ed.) E. Lee, \& M. Vivarelli, Understanding globalization, employment and poverty reduction, Palgrave Macmillan, New York, 211-243.

World Bank, (2020). https://data.worldbank.org/ (Erişim Tarihi, 5 Nisan 2020). 